\title{
Agregados amiloides: rol en desórdenes de conformación proteica
}

\author{
CLAUDIA DURAN-ANIOTZ ${ }^{1,2, a}$, INÉS MORENO-GONZALEZ ${ }^{1, \mathrm{~b}}$, \\ RODRIGO MORALES ${ }^{1, b}$
}

\section{Amyloid aggregates: role in protein misfolding disorders}

Misfolding and aggregation of proteins are the main features of a group of diseases termed Protein Misfolding Disorders (PMDs). PMDs include Alzheimer's disease and Transmissible Spongiform Encephalopathies, among many others. The deposition of protein aggregates is the main responsible for tissue damage and the consequent clinical signs generated in such disorders. In this review, we will focus in the role of protein aggregates in these diseases and in the putative mechanisms by which they exert their toxicity.

(Rev Med Chile 2013; 141: 495-505).

Key words: Alzheimers disease; Amyloid; Prion diseases; Protein misfolding; Protestasis deficiencies.

'Mitchell Center for Alzheimer's disease and related Brain Disorders, Department of Neurology, University of Texas Medical School at Houston, 6431 Fannin Street, Houston, Texas, 77030, USA.

${ }^{2}$ Universidad de los Andes, Facultad de Medicina, Av. San Carlos de Apoquindo 2200, Las Condes,

Santiago, Chile.

${ }^{\mathrm{a}} \mathrm{M} . \mathrm{Sc}$

${ }^{b} P h . D$.

Conflictos de Intereses: Los autores de este trabajo no tienen conflictos de intereses que declarar.

Recibido el 24 de enero de 2012 aceptado el 11 de julio de 2012

Correspondencia a:

Dr. Rodrigo Morales. Mitchell Center for Alzheimer's disease and related Brain Disorders, Department of Neurology, University of Texas Medical School at Houston, 6431 Fannin Street, Houston, Texas,

77030, USA.

Fax: 1-713-500-0773

E-mail: Rodrigo.MoralesLoyola@ uth.tmc.edu
L as proteínas deben adquirir un plegamiento adecuado, el cual depende tanto de su secuencia aminoacídica como de la maquinaria presente en la célula. Los procesos anormales de plegamiento, inducidos por diversas situaciones de estrés en el ambiente intra- o extra-celular, mutaciones u otros eventos, pueden resultar en la pérdida de las funciones fisiológicas de la proteína o en la generación de estructuras tóxicas para la célula, provocando acontecimientos patológicos ${ }^{1-3}$. Los eventos de plegamientos anómalos (conocidos como protein misfolding) que desembocan en la agregación de proteínas en tejidos específicos ${ }^{1}$, han sido asociados a muchas enfermedades. Debido al origen común desde el punto de vista molecular, este grupo de enfermedades se ha denominado desórdenes de conformación proteica (DCP). Los DCP incluyen muchos síndromes clínicos como la enfermedad de Alzheimer (EA), la enfermedad de Parkinson (EP), la enfermedad de Huntington (EH), la diabetes tipo-2 (DT2) y las encefalopatías espongiformes transmisibles (EET) o enfermedades producidas por priones, entre otras ${ }^{1}$.

Se ha sugerido que la deposición de agregados proteicos en estas enfermedades es el principal responsable de los daños tisulares y de los con- secuentes cuadros clínicos generados. Los mecanismos por los que estas estructuras ejercen sus efectos no han sido completamente descritos en la actualidad. Las proteínas que constituyen los agregados proteicos en los DCP son específicas de cada una de las enfermedades en las que están implicadas, causando múltiples efectos en diferentes tejidos. De esta forma, el péptido $\beta$-amiloide $(\beta A)$ y la proteína tau están involucrados en la EA; la proteína del prion con una conformación anormal (conocida como $\mathrm{PrP}^{\mathrm{sc}}$ ), en las EET; la $\alpha$-sinucleína, en la EP; y la huntingtina, en la EH. Considerando el incremento de la población de edad avanzada y que muchas de estas enfermedades están íntimamente asociadas al envejecimiento, se estima que el número de pacientes afectados por algún DCP aumentará considerablemente en los próximos años ${ }^{4}$. Si tomamos en cuenta estos pronósticos y el hecho de que en este momento no existen métodos diagnósticos o terapéuticos efectivos para estas enfermedades, la investigación biomédica enfocada a entender las bases moleculares de estas condiciones patológicas es de vital importancia.

En esta revisión nos enfocaremos en el papel y mecanismos por los cuales los agregados proteicos ejercen su actividad y, en consecuencia, desenca- 
denan los DCP. Nos centraremos principalmente en dos tipos de DCP por su prevalencia e interés a nivel biomédico: la EA y las EET.

\section{Bases moleculares de los desórdenes de conformación proteica: el modelo de nucleación-polimerización}

En los DCP, los agregados proteicos o "amiloides" se componen de diferentes proteínas, sin embargo, estas estructuras son similares desde el punto de vista morfológico y bioquímico. Desde un enfoque estructural, las proteínas presentes en este tipo de organizaciones se caracterizan por tener plegamiento del tipo $\beta$, favoreciendo la hidrofobicidad y la agregación en estructuras específicas denominadas hoja $\beta$-plegada ${ }^{1,5}$. Esta disposición conformacional, confiere a las proteínas resistencia a proteólisis, desnaturalización y a mecanismos generales de eliminación presentes en la célula. Los factores celulares que pueden guiar estos procesos de plegamiento anómalo han sido parcialmente identificados. Entre ellos, quizás el más importante, está relacionado con las diferencias en la secuencia proteica. Se ha descrito que sustituciones puntuales en la secuencia aminoacídica promueven una conformación amiloidogénica, la cual puede favorecer la agregación y la subsecuente progresión patológica ${ }^{6}$.

Los procesos de agregación proteica en estas enfermedades se caracterizan por ser lentos y organizados. Uno de los modelos más aceptados para la formación de estructuras amiloidogénicas es el de nucleación-polimerización ${ }^{3,7}$. Brevemente, este modelo propone una cinética particular definida por dos fases disímiles de agregación ${ }^{3}$ (Figura 1). La primera de ellas, denominada fase de retardo o lag phase, involucra los primeros eventos de formación de "núcleos" o "semillas" de polimerización a expensas de intermediarios solubles o formas aberrantes (por ejemplo, mutantes) de estas proteínas. La formación de estas pequeñas estructuras oligoméricas da paso a la segunda

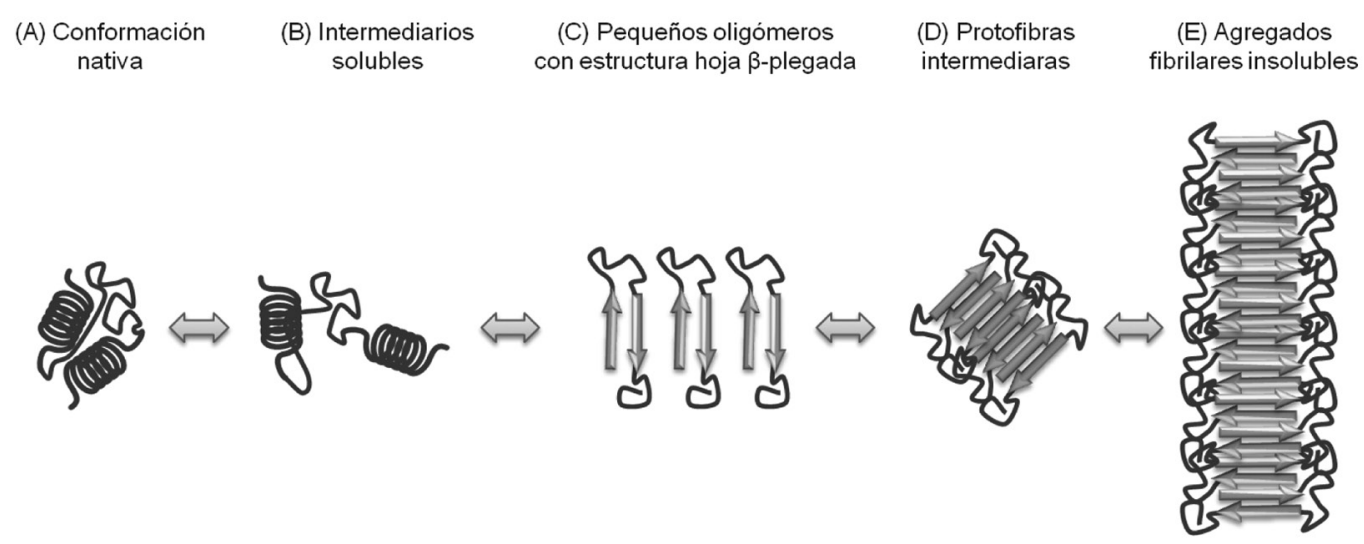

Figura 1. Modelo de nucleación-polimerización en la formación de estructuras amiloides. La conformación nativa de una proteína (A), normalmente ligada a una adecuada función biológica, está en equilibrio con muchas otras conformaciones posibles. Entre ellas, formas parcialmente plegadas (B) pueden desembocar en estructuras anómalas (C-E) asociadas a los DCP. En el proceso de agregación de estas proteínas se distinguen dos etapas predominantes. La primera (fase de retardo) incluye la generación de los primeros núcleos de agregación, mientras que la segunda (fase exponencial) corresponde al crecimiento de estas unidades a partir de los núcleos de agregación previamente formados. Las proteínas anómalamente plegadas en estas enfermedades se distribuyen comúnmente en estructuras que incluyen pequeños oligómeros (C), protofibras (D), y agregados fibrilares insolubles (E). La adición de agregados previamente formados es capaz de inducir la oligomerización de unidades monoméricas solubles, evento que acorta la fase de retardo y que explica parcialmente los mecanismos de infectividad existentes en las EET. 
fase en este proceso (o fase exponencial), donde el reclutamiento exponencial de nuevas unidades a los agregados previamente formados, resulta en una gran carga de estructuras amiloides, las cuales se distribuyen en un amplio espectro de organizaciones como pequeños oligómeros, protofibras, fibras y, en algunos casos, placas amiloides ${ }^{5,8}$.

A pesar de la relación existente entre este tipo de agregados y el desarrollo de la enfermedad, los mecanismos por los que se produce el típico daño celular en estas patologías es aún un tema controvertido. Estudios recientes sugieren que los oligómeros solubles serían las especies más tóxicas en estas enfermedades 9 . En base a estos resultados, se ha postulado que grandes agregados compuestos de fibras y placas amiloides podrían actuar como un mecanismo de defensa al atrapar estas partículas tóxicas y encapsularlas, reduciendo su actividad citotóxica ${ }^{10}$.

\section{Teorías de la disfunción y muerte celular en los desórdenes de conformación proteica}

Las manifestaciones clínicas observadas en los DCP son la consecuencia de una serie de alteraciones presuntamente producidas por las proteínas con conformación anómala. Estas alteraciones están directamente relacionadas con la disfunción y la muerte celular. En la actualidad, se han descrito tres hipótesis que explicarían los daños tisulares y sistémicos generados en estas enfermedades: i) pérdida de la función normal ejercida por la proteína; ii) ganancia en toxicidad de los nuevos agregados moleculares generados; e iii) inducción de procesos inflamatorios (Figura 2).

\section{Hipótesis de pérdida de la función}

Una de las hipótesis en relación a la progresión clínica y patológica en los DCP es que la proteína involucrada, al adquirir una nueva conformación, perdería su función original, produciéndose así un quiebre en procesos esenciales para el desarrollo y supervivencia celular. En la esclerosis lateral amiotrófica, la pérdida en la funcionalidad de la superóxido dismutasa-1, podría proporcionar una susceptibilidad excesiva de las células ante eventos de estrés oxidativo ${ }^{11}$. Para otras proteínas, como el péptido $\beta A$ en la EA o la proteína celular del prion $\left(\mathrm{PrP}^{\mathrm{C}}\right)$ en las EET, su función biológica no ha sido descrita satisfactoriamente ${ }^{12-14}$.
Numerosas funciones le han sido atribuidas a la PrP, entre las que destaca su asociación en funciones de neuroprotección, ya sea como receptora $^{15,16}$, transductora ${ }^{17,18}$ o como molécula antioxidante ${ }^{19,20}$. Diversos estudios muestran que la $\mathrm{PrP}$ es capaz de reducir la tasa de muerte celular tras exposición a estrés oxidativo y, por el contrario, su deficiencia produce un aumento de la misma ${ }^{21-24}$. Otros estudios han descrito que las repeticiones de octapéptidos en su región $\mathrm{N}$-terminal son capaces de unir iones de cobre divalente, relacionando así a la $\mathrm{PrP}^{\mathrm{C}}$ con la homeostasis de este catión en la zona sináptica ${ }^{25}$. De hecho, pacientes afectados con la enfermedad de Creutzfeldt-Jakob (ECJ) presentan un aumento de hasta $50 \%$ en los niveles de ión cobre cerebral ${ }^{26}$. Adicionalmente, varias proteínas han sido asociadas a PrP, dentro de las cuales destacan importantes moléculas transductoras como Bcl-2, Hsp60, STI1, Fyn, PKA, PI3K/Akt, entre otras $^{16,27}$. Por otro lado, la $\operatorname{PrP}^{\mathrm{C}}$ ha sido relacionada con eventos pro-apoptóticos, complicando aún más este escenario ${ }^{28}$. Recientemente, se ha descrito a la $\mathrm{PrP}^{\mathrm{C}}$ como un receptor de oligómeros tóxicos de $\beta \mathrm{A}^{15}$, hallazgo que también ha suscitado controversias $^{29}$. Sin embargo, hasta el momento, la única función clara de la $\mathrm{PrP}^{\mathrm{C}}$ es ser la fuente a partir de la cual los priones infecciosos son generados, ya que los animales que carecen de esta proteína son viables y completamente resistentes a la infección mediada por $\mathrm{PrP}^{\mathrm{Sc} 30}$.

Para el caso de la proteína precursora amiloide (PPA), molécula a partir de la cual se forma el $\beta A$, el panorama es distinto. Una de las funciones atribuidas a esta proteína es, al igual que para la $\operatorname{PrP}$, la capacidad de unir ión cobre ${ }^{31}$. Otras propiedades asociadas son la de actuar como factor de crecimiento ${ }^{32}$, mediador de adhesión celular ${ }^{33,34}$, regulador intraneuronal de $\mathrm{calcio}^{35}$ y receptor celular $^{36}$. Además, el $\beta$ A ha sido asociado como sustrato proteolítico de la proteína degradadora de la insulina, confiriéndole propiedades en la regulación de este importante metabolito ${ }^{37}$. Los animales deficientes en la PPA presentan anomalías motoras, que podrían tener su origen en deficiencias nerviosas y/o musculares ${ }^{38,39}$. Adicionalmente, estos animales también presentan otras características neuropatológicas como neuroinflamación $^{39}$ y fallos en la memoria a largo plazo ${ }^{38,40,41}$, pero en ningún caso una condición patológica que simule a la EA.

En conclusión, para las patologías de nuestro 


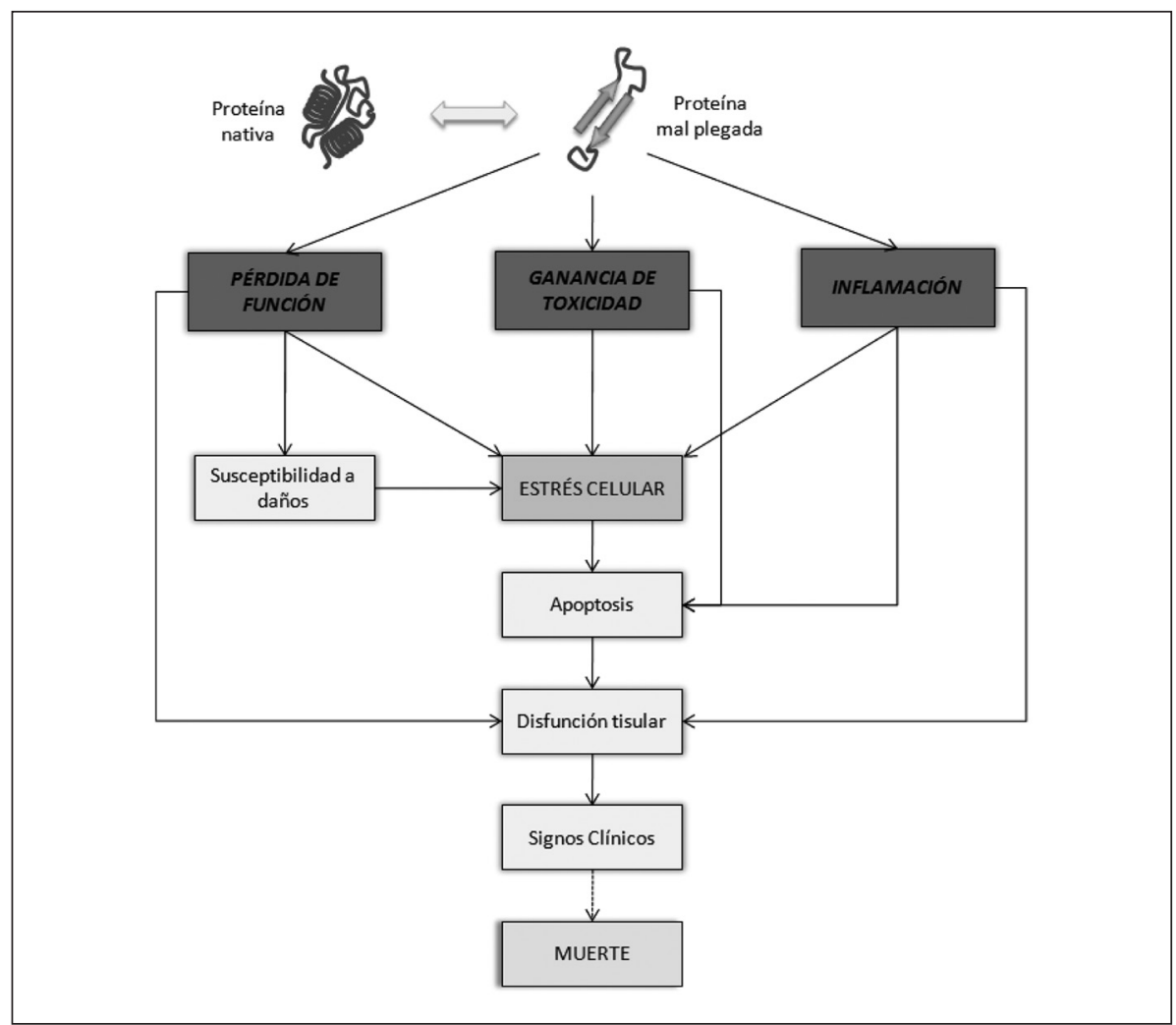

Figura 2. Mecanismos propuestos para el daño tisular causado por los agregados amiloides en los DCP. La pérdida de la función normal de la proteína, la ganancia de toxicidad de nuevas conformaciones y la inducción de procesos inflamatorios, son los mecanismos propuestos de cómo los agregados proteicos ejercen su función en los DCP. Por una parte, estos cambios conformacionales pueden resultar en la pérdida de las funciones fisiológicas específicas de una proteína, evento que podría causar daños considerables en el organismo. Alternativamente, estos cambios estructurales pueden concluir en la producción y acumulación de entidades tóxicas, sensibilizando a la célula ante eventos de estrés que pueden terminar en su muerte. Además, la nueva conformación adquirida por estas proteínas puede interactuar con diferentes receptores de la superficie neuronal o con elementos de la microglía y astrocitos, desencadenando cascadas transduccionales nocivas para la célula (ver texto). La combinatoria de todos estos eventos, que desembocan en la muerte o disfunción celular, posteriormente genera una descompensación tisular y sintomatología específica, lo que en la gran mayoría de los casos potencia o concluye en la muerte del individuo.

interés, no es posible afirmar si la pérdida de la función proteica es la causa de la progresión patológica. Lo que es claro es que en ningún caso la ausencia de estas moléculas explica satisfactoriamente la sinaptotoxicidad y muerte neuronal observadas. Es por ese motivo que la hipótesis de la ganancia de la toxicidad es la más aceptada en la actualidad.

\section{Hipótesis de la ganancia de toxicidad}

Una de las teorías fundamentales acerca de la muerte neuronal en las EET y en otros DCP señala a que la nueva conformación adquirida por la proteína involucrada podría tener efectos tóxicos para la célula ${ }^{42-44}$. En la gran mayoría de los DCP, la acumulación del confórmero mal plegado ejercería la citotoxicidad observada ${ }^{1}$. En general, la muerte celular en estas patologías puede ocurrir por diversas rutas, sin embargo, la apoptosis es el principal evento implicado ${ }^{44}$. Distintos trabajos en modelos animales de EET muestran una clara activación apoptótica ${ }^{45-49}$. Estos estudios han sido complementados analizando tejidos obtenidos de pacientes ${ }^{50}$, confirmando la existencia de moléculas características de procesos apoptóticos.

Como ha sido descrito en muchos experimentos realizados in vitro, la región 106-126 de la PrP se encuentra altamente relacionada con la 
neurotoxicidad en las EET ${ }^{51,52}$. Este fragmento es rico en estructura $\beta$ y es parcialmente resistente a la acción de la proteinasa $\mathrm{K}$, características clásicamente asociadas a los priones infecciosos. Los procesos de muerte celular relacionados con este péptido están relacionados a un aumento de los niveles de $\mathrm{Ca}^{2+}$ en el espacio citoplasmático ${ }^{46}$ y a la despolarización de membranas, posiblemente generada por la formación de canales iónicos ${ }^{53}$. Estos eventos son seguidos por la activación de la calpaína y posterior disfunción mitocondrial, lo que concluye en la activación de la caspasa- $3^{52}$. Evidencia adicional sugiere que la $\operatorname{PrP}$ es capaz de activar una respuesta reticular característica ante proteínas mal plegadas, la que finalmente desemboca en eventos apoptóticos ${ }^{46}$. Adicionalmente, los fragmentos de $\beta \mathrm{A}\left(\beta \mathrm{A}_{40}\right.$ y $\left.\beta \mathrm{A}_{42}\right)$ fisiológicamente relevantes con conformación amiloidogénica han sido reportados como citotóxicos ${ }^{54-58}$. Así como en las EET, rutas similares de muerte celular han sido asociadas al $\beta$ A en la $\mathrm{EA}^{44,59-62}$.

Análisis post mortem de cerebros de pacientes afectados con las enfermedades de Alzheimer, Creutzfeldt-Jakob e insomnio fatal familiar, muestran que la deposición proteica no se encuentra siempre relacionada con la pérdida neuronal. El hecho de si el responsable de la toxicidad celular observada es realmente la acumulación de la proteína anómalamente plegada o un intermediario soluble, aún se desconoce ${ }^{63}$. La identificación reciente de oligómeros como las partículas más nocivas en estas enfermedades ha abierto nuevas puertas tanto para la investigación básica como en la búsqueda de nuevas estrategias terapéuticas para combatir a estas enfermedades ${ }^{64-68}$.

\section{Inducción de procesos inflamatorios}

El sistema inmunológico juega un rol esencial en el mantenimiento de la homeostasis tisular, confiriendo al organismo protección frente a agresiones tanto internas como externas. Las enfermedades neurodegenerativas se caracterizan, en general, por la aparición de un severo proceso neuroinflamatorio ${ }^{69}$. En el cerebro, la mayoría de las células inmunes residentes son las células microgliales (macrófagos), las cuales están en constante actividad ${ }^{70}$. Las células astrogliales, además de tener funciones de soporte, también intervienen en la respuesta inflamatoria. En consecuencia, la microglía y los astrocitos son las principales células que participan en la respuesta neuroinflamatoria.
$\mathrm{Al}$ inicio de la enfermedad, esta reacción inflamatoria es necesaria y beneficiosa para el organismo, pero cuando ésta se produce de forma exacerbada y/o crónica puede causar graves daños titulares e incluso agravar el desarrollo de la enfermedad.

En particular, los agregados proteicos de $\beta \mathrm{A}$ y $\mathrm{PrP}^{\mathrm{Sc}}$, son los responsables directos o indirectos de la existencia de un proceso inflamatorio, determinado por una activación de la microglía y la posterior producción de citoquinas pro-inflamatorias, así como por la aparición de astrocitos reactivos, que pueden generar productos tóxicos que inducen muerte neuronal, tales como citoquinas inflamatorias, aminoácidos excitadores y especies reactivas de oxígeno $(E R O)^{71-74}$.

Bajo condiciones fisiológicas, la microglía se encuentra en estado de reposo, asociado con la producción de factores anti-inflamatorios ${ }^{70}$. En respuesta a la acumulación o agregación proteica, la microglía se activa y es reclutada hacia la zona donde se encuentran estos agregados ${ }^{70}$. Muchas veces, esta respuesta inflamatoria involucra la migración de células circulantes periféricas al cerebro. Después de la activación, la microglía aumenta la expresión de factores pro-inflamatorios como citoquinas, quimioquinas y proteínas del complejo mayor de histocompatibilidad, relacionadas con la presentación antigénica ${ }^{75}$. La correcta activación microglial, seguida de una apropiada activación linfocitaria, tiene efectos neuroprotectores, favoreciendo la fagocitosis de células muertas, la eliminación de productos de desecho y la liberación de factores que pueden promover la sobrevida y desarrollo de neuronas ${ }^{76}$. Por el contrario, si la activación es exacerbada o crónica, las células del sistema inmune pueden producir estrés oxidativo, provocando neurotoxicidad y posteriormente, neurodegeneración ${ }^{75}$. La microgliosis se considera uno de los primeros cambios que aparecen con el inicio de los DCP. En la EA, se cree que la formación del péptido $\beta A$ desencadena directamente la activación microglial ${ }^{77}$. Por este motivo, las zonas donde inicialmente se deposita el $\beta$ A tanto en humanos como en modelos animales son las que muestran mayor activación de células microgliales (neocorteza, hipocampo y corteza entorrinal $)^{73,74,78,79}$. Esta activación se produce durante la transición de una placa difusa a una placa primitiva ${ }^{80}$, formas que adoptan los agregados de $\beta$ A conforme se desarrolla la enfermedad. El $\beta$ A puede atraer y activar a la microglía, 
generando una acumulación microglial alrededor de los depósitos ${ }^{81,82}$. Posiblemente, la microglía actúe de forma fagocítica para eliminar las placas amiloidogénicas ${ }^{83-86}$.

Por otra parte, la microglía puede expresar receptores de adhesión a $\beta$ A fibrilar, lo que conduce a la liberación de ERO, secreción de interleuquina$1 \beta$ (IL-1 $\beta$ ), IL-6, factor de necrosis tumoral- $\alpha$ y quimioquinas ${ }^{71,72,87}$. Del mismo modo ocurre en la activación inmune típica de la enfermedad de Creutzfeldt-Jakob ${ }^{88}$. La activación de la microglía y la posterior liberación de factores relacionados con la inflamación son beneficiosas para frenar el desarrollo de la enfermedad. La ausencia de microglía en modelos murinos de la EA provoca un incremento en la formación de placas amiloides y muerte neuronal ${ }^{89}$.

Por otro lado, los astrocitos juegan un papel esencial en el proceso inflamatorio que ocurre en la EA y en las EET, actuando de forma similar a como lo hace la microglía. Estas células se concentran en las regiones de depósito de las placas de $\beta \mathrm{A}$ y $\mathrm{PrP}^{\mathrm{Sc}}$, secretando factores pro-inflamatorios, como citoquinas, prostaglandinas, leucotrienos, factores de coagulación, óxido nítrico sintasa y ERO ${ }^{90,91}$. Su infiltración y acumulación alrededor de las placas, al igual que la microglía, permite la fagocitosis de los péptidos amiloides ${ }^{91-94}$, manteniendo un balance entre la producción y la eliminación del péptido. En la corteza entorrinal, en el hipocampo y en el subículo de pacientes que padecen de la EA, se ha encontrado una correlación positiva entre el número de placas amiloides y el número de astrocitos ${ }^{95}$, indicando la importante función que estas células ejercen. En relación a los ovillos neurofibrilares formados por la proteína tau hiperfosforilada, sólo se han correlacionado con la cantidad de astrocitos en la corteza entorrinal. Adicionalmente, mientras que la densidad del número de placas no se correlaciona con la severidad de la EA, sí lo hace el número de astrocitos inmunorreactivos tanto en la corteza entorrinal como en el hipocampo ${ }^{95}$. Se ha descrito que la presencia de IL-1 promueve la activación de los astrocitos mediante el ligando de CXCR3 en las patologías producidas por priones ${ }^{96}$. Estos estudios muestran que cambios en la expresión de ligandos CXC pueden ser detectados en estadios asintomáticos de las EET, lo que sugiere que estas quimioquinas podrían ser factores importantes que promueven la neurodegeneración en las enfermedades desen- cadenadas por priones ${ }^{97,98}$.

Aún se desconoce si la neuroinflamación es una consecuencia secundaria al proceso neurodegenerativo o es una de las causas que podrían provocar su aparición y desarrollo. La contribución de la neuroinflamación a la disfunción y progresión de estas enfermedades aún no ha sido completamente estudiada, aunque gran parte de los estudios realizados hasta el momento apuntan a que su función es crucial en el proceso neurodegenerativo. Por este motivo, se han realizado un gran número de investigaciones con el propósito de analizar la posible relación entre el uso de drogas anti-inflamatorias y una menor probabilidad de desarrollar algún tipo de DCP, incluso, planteando el uso de estos fármacos como una posible terapia para disminuir los síntomas asociados en la EA. Datos epidemiológicos han mostrado una menor prevalencia de la EA en pacientes medicados regularmente con drogas anti-inflamatorias no esteroideas (AINEs) ${ }^{99-101}$. Adicionalmente, análisis experimentales han reportado una disminución tanto en la sintomatología como en la acumulación de placas amiloides en forma independiente a la actividad de la ciclo-oxigenasa tras la administración de ibuprofeno ${ }^{102-104}$. Sin embargo, estudios recientes muestran resultados contradictorios, posiblemente debido a que una adecuada respuesta inmune, aunque no crónica, es beneficiosa en el inicio de la enfermedad ${ }^{105,106}$.

\section{Conclusiones}

Se han propuesto múltiples mecanismos por los cuales los agregados proteicos conducen a los daños tisulares y la posterior manifestación clínica, incluyendo la pérdida de la función normal de la proteína, la ganancia en toxicidad de las nuevas conformaciones y la inducción de procesos inflamatorios. Actualmente, no se ha descrito ningún mecanismo que explique satisfactoriamente la degeneración tisular asociada a estos desórdenes. Es posible que la suma o acumulación de estos eventos sea la causa de la neurodegeneración y la posterior manifestación clínica que en muchos casos termina en la muerte del individuo.

Hoy en día, se están realizando grandes esfuerzos enfocados a combatir estas enfermedades. Éstos incluyen la inmunización activa o pasiva ${ }^{107-110}$ y estrategias no inmunológicas, como inhibidores 
de secretasas ${ }^{111}$ y compuestos anti-agregación ${ }^{112}$. La manipulación del sistema inmune con el propósito de erradicar los agregados proteicos ha sido ampliamente estudiada como estrategia terapéutica para la EA desde hace ya varios años ${ }^{113}$. En este momento, para las EET, las estrategias inmunoterapéuticas abarcan desde anticuerpos contra la $\mathrm{PrP}^{\mathrm{Sc} 114,115}$ hasta la obtención de células involucradas en la eliminación de este agregado ${ }^{116}$. Adicionalmente, en la EA, la inhibición farmacológica de las enzimas responsables de la formación del $\beta A(\gamma$ - y $\beta$-secretasa) es una estrategia importante para bloquear la producción de este amiloide ${ }^{111}$.

El estudio de los mecanismos que regulan la agregación proteica, como también los efectos tóxicos de las proteínas implicadas en los DCP, es crucial para desarrollo de terapias para tratar o prevenir este tipo de enfermedades.

\section{Referencias}

1. Soto C. Unfolding the role of Protein Misfolding in Neurodegenerative Diseases. Nature Rev Neurosci 2003; 4: 49-60.

2. Dobson CM. Protein misfolding, evolution and disease. Trends in Biochemical Sciences 1999; 24 (9): 329-32.

3. Soto C. Protein misfolding and disease; protein refolding and therapy. FEBS Lett 2001; 498: 204-7.

4. Reitz C, Brayne C, Mayeux R. Epidemiology of Alzheimer disease. Nat Rev Neurol 2011; 7 (3): 137-52.

5. Blake CC, Serpell LC, Sunde M, Sandgren O, Lundgren E. A molecular model of the amyloid fibril. Ciba Found Symp 1996; 199: 6-15.

6. Hardy J, Gwinn-Hardy K. Genetic classification of primary neurodegenerative disease. Science 1998.

7. Jarrett JT, Lansbury PT Jr. Seeding "one-dimensional crystallization" of amyloid: a pathogenic mechanism in Alzheimer's disease and scrapie? Cell 1993; 73 (6): 10558.

8. Moreno-González I, Soto C. Misfolded protein aggregates: mechanisms, structures and potential for disease transmission. Semin Cell Dev Biol 2011; 22 (5): 482-7.

9. Haass C, Selkoe DJ. Soluble protein oligomers in neurodegeneration: lessons from the Alzheimer's amyloid beta-peptide. Nat Rev Mol Cell Biol 2007; 8 (2): 101-12.

10. Soto C. Plaque busters: strategies to inhibit amyloid formation in Alzheimer's disease. Mol Med Today 1999; 5 (8): 343-50.

11. Deng HX, Hentati A, Tainer JA, Iqbal Z, Cayabyab A, Hung WY, et al. Amyotrophic lateral sclerosis and structural defects in $\mathrm{Cu}, \mathrm{Zn}$ superoxide dismutase. Science
1993; 261 (5124): 1047-51.

12. Hetz C, Maundrell K, Soto C. Is loss of function of the prion protein the cause of prion disorders? Trends Mol Med 2003; 9 (6): 237-43.

13. Aguzzi A, Sigurdson C, Heikenwalder M. Molecular Mechanisms of Prion Pathogenesis. Annu Rev Pathol 2007.

14. Chang KA, Suh YH. Possible roles of amyloid intracellular domain of amyloid precursor protein. BMB Rep 2010; 43 (10): 656-63.

15. Lauren J, Gimbel DA, Nygaard HB, Gilbert JW, Strittmatter SM. Cellular prion protein mediates impairment of synaptic plasticity by amyloid-beta oligomers. Nature 2009; 457 (7233): 1128-32.

16. Roucou X, Gains M, LeBlanc AC. Neuroprotective functions of prion protein. J Neurosci Res 2004; 75 (2): 153-61.

17. Wisniewski T, Aucouturier P, Soto C, Frangione B. The prionoses and other conformational disorders. Amyloid 1998; 5 (3): 212-24.

18. Hetz C, Soto C. Protein misfolding and disease: the case of prion disorders. Cell Mol Life Sci 2003; 60 (1): 13343.

19. Brown DR, Nicholas RS, Canevari L. Lack of prion protein expression results in a neuronal phenotype sensitive to stress. J Neurosci Res 2002; 67 (2): 211-24.

20. Wong BS, Pan T, Liu T, Li R, Petersen RB, Jones IM, et al. Prion disease: A loss of antioxidant function? Biochem Biophys Res Commun 2000; 275 (2): 249-52.

21. Brown DR, Wong BS, Hafiz F, Clive C, Haswell SJ, Jones IM. Normal prion protein has an activity like that of superoxide dismutase. Biochem J 1999; 344 Pt 1: 1-5.

22. Wong BS, Clive C, Haswell SJ, Williamson RA, Burton DR, Gambetti P, et al. Copper has differential effect on prion protein with polymorphism of position 129 . Biochem Biophys Res Commun 2000; 269 (3): 726-31.

23. Wong BS, Pan T, Liu T, Li R, Gambetti P, Sy MS. Differential contribution of superoxide dismutase activity by prion protein in vivo. Biochem Biophys Res Commun 2000; 273 (1): 136-9.

24. Brown DR. PrPSc-like prion protein peptide inhibits the function of cellular prion protein. Biochem J 2000; 352 Pt 2: 511-8.

25. Ruiz FH, Silva E, Inestrosa NC. The N-terminal tandem repeat region of human prion protein reduces copper: role of tryptophan residues. Biochem Biophys Res Commun 2000; 269 (2): 491-5.

26. Wong BS, Chen SG, Colucci M, Xie Z, Pan T, Liu T, et al. Aberrant metal binding by prion protein in human prion disease. J Neurochem 2001; 78 (6): 1400-8.

27. Gauczynski S, Hundt C, Leucht C, Weiss S. Interaction 
of prion proteins with cell surface receptors, molecular chaperones, and other molecules. Adv Protein Chem 2001; 57: 229-72.

28. Paitel E, Fahraeus R, Checler F. Cellular prion protein sensitizes neurons to apoptotic stimuli through Mdm2regulated and p53-dependent caspase 3-like activation. J Biol Chem 2003; 278 (12): 10061-6.

29. Balducci C, Beeg M, Stravalaci M, Bastone A, Sclip A, Biasini E, et al. Synthetic amyloid-beta oligomers impair long-term memory independently of cellular prion protein. Proc Natl Acad Sci USA 2010; 107 (5): 2295-300.

30. Bueler H, Fischer M, Lang Y, Bluethmann H, Lipp HP, DeArmond SJ, et al. Normal development and behaviour of mice lacking the neuronal cell-surface PrP protein. Nature 1992; 356 (6370): 577-82.

31. Hesse L, Beher D, Masters CL, Multhaup G. The beta A4 amyloid precursor protein binding to copper. FEBS Lett 1994; 349 (1): 109-16.

32. Saitoh T, Sundsmo M, Roch JM, Kimura N, Cole G, Schubert D, et al. Secreted form of amyloid beta protein precursor is involved in the growth regulation of fibroblasts. Cell 1989; 58 (4): 615-22.

33. Schubert D, Jin LW, Saitoh T, Cole G. The regulation of amyloid beta protein precursor secretion and its modulatory role in cell adhesion. Neuron 1989; 3 (6): 689-94.

34. Milward EA, Papadopoulos R, Fuller SJ, Moir RD, Small $\mathrm{D}$, Beyreuther $\mathrm{K}$, et al. The amyloid protein precursor of Alzheimer's disease is a mediator of the effects of nerve growth factor on neurite outgrowth. Neuron 1992; 9 (1): 129-37.

35. Mattson MP, Barger SW, Cheng B, Lieberburg I, SmithSwintosky VL, Rydel RE. beta-Amyloid precursor protein metabolites and loss of neuronal Ca2+ homeostasis in Alzheimer's disease. Trends Neurosci 1993; 16 (10): 409-14.

36. Nishimoto I, Okamoto T, Matsuura Y, Takahashi S, Okamoto T, Murayama Y, et al. Alzheimer amyloid protein precursor complexes with brain GTP-binding protein G(o). Nature 1993; 362 (6415): 75-9.

37. Kurochkin IV, Goto S. Alzheimer's beta-amyloid peptide specifically interacts with and is degraded by insulin degrading enzyme. FEBS Lett 1994; 345 (1): 33-37.

38. Senechal Y, Kelly PH, Dev KK. Amyloid precursor protein knockout mice show age-dependent deficits in passive avoidance learning. Behav Brain Res 2008; 186 (1): 126-32.

39. Zheng H, Jiang M, Trumbauer ME, Sirinathsinghji DJ, Hopkins R, Smith DW, et al. beta-Amyloid precursor protein-deficient mice show reactive gliosis and decreased locomotor activity. Cell 1995; 81 (4): 525-31.
40. Dawson GR, Seabrook GR, Zheng H, Smith DW, Graham S, O'Dowd G, et al. Age-related cognitive deficits, impaired long-term potentiation and reduction in synaptic marker density in mice lacking the beta-amyloid precursor protein. Neuroscience 1999; 90 (1): 1-13.

41. Seabrook GR, Smith DW, Bowery BJ, Easter A, Reynolds T, Fitzjohn SM, et al. Mechanisms contributing to the deficits in hippocampal synaptic plasticity in mice lacking amyloid precursor protein. Neuropharmacology 1999; 38 (3): 349-59.

42. Soto C, Satani N. The intricate mechanisms of neurodegeneration in prion diseases. Trends Mol Med 2010; 17 (1): 14-24.

43. Prusiner SB. Prions. Proc Natl Acad Sci U S A 1998; 95 (23): 13363-83.

44. Morales R, Hetz C, Soto C. Signaling pathways controling prion neurotoxicity: role of endoplasmic reticulum stress-mediated apoptosis; in: Brown DR, (ed): Neurodegeneration and Prion Disease. New York, USA, Springer, 2005, pp 319-44.

45. Jesionek-Kupnicka D, Kordek R, Buczynski J, Liberski PP. Apoptosis in relation to neuronal loss in experimental Creutzfeldt-Jakob disease in mice. Acta Neurobiol Exp (Wars) 2001; 61 (1): 13-9.

46. Hetz C, Russelakis-Carneiro M, Maundrell K, Castilla J, Soto C. Caspase-12 and endoplasmic reticulum stress mediate neurotoxicity of pathological prion protein. EMBO J 2003; 22 (20): 5435-45.

47. Williams A, Lucassen PJ, Ritchie D, Bruce M. PrP deposition, microglial activation, and neuronal apoptosis in murine scrapie. Exp Neurol 1997; 144 (2): 433-8.

48. Fairbairn DW, Carnahan KG, Thwaits RN, Grigsby RV, Holyoak GR, O'Neill KL. Detection of apoptosis induced DNA cleavage in scrapie-infected sheep brain. FEMS Microbiol Lett 1994; 115 (2-3): 341-6.

49. Jesionek-Kupnicka D, Buczynski J, Kordek R, Liberski PP. Neuronal loss and apoptosis in experimental Creutzfeldt-Jakob disease in mice. Folia Neuropathol 1999; 37 (4): 283-6.

50. Gray F, Adle-Biassette H, Chretien F, Ereau T, Delisle MB, Vital C. [Neuronal apoptosis in human prion diseases]. Bull Acad Natl Med 1999; 183 (2): 305-20.

51. Forloni G, Angeretti N, Chiesa R, Monzani E, Salmona $\mathrm{M}$, Bugiani $\mathrm{O}$, et al. Neurotoxicity of a prion protein fragment. Nature 1993; 362 (6420): 543-6.

52. O'Donovan CN, Tobin D, Cotter TG. Prion protein fragment PrP-(106-126) induces apoptosis via mitochondrial disruption in human neuronal SH-SY5Y cells. J Biol Chem 2001; 276 (47): 43516-23.

53. Lin MC, Mirzabekov T, Kagan BL. Channel formation by a neurotoxic prion protein fragment. J Biol Chem 1997; 
272 (1): 44-7.

54. Mattson MP, Cheng B, Davis D, Bryant K, Lieberburg I, Rydel RE. beta-Amyloid peptides destabilize calcium homeostasis and render human cortical neurons vulnerable to excitotoxicity. J Neurosci 1992; 12 (2): 376-89.

55. Mark RJ, Hensley K, Butterfield DA, Mattson MP. Amyloid beta-peptide impairs ion-motive ATPase activities: evidence for a role in loss of neuronal Ca2+ homeostasis and cell death. J Neurosci 1995; 15 (9): 6239-49.

56. Pike CJ, Walencewicz AJ, Glabe CG, Cotman CW. In vitro aging of beta-amyloid protein causes peptide aggregation and neurotoxicity. Brain Res 1991; 563 (1-2): 311-4.

57. Pike CJ, Walencewicz AJ, Glabe CG, Cotman CW. Aggregation-related toxicity of synthetic beta-amyloid protein in hippocampal cultures. Eur J Pharmacol 1991; 207 (4): 367-8.

58. Forloni G, Chiesa R, Smiroldo S, Verga L, Salmona M, Tagliavini F, et al. Apoptosis mediated neurotoxicity induced by chronic application of beta amyloid fragment 25-35. Neuroreport 1993; 4 (5): 523-6.

59. Lustbader JW, Cirilli M, Lin C, Xu HW, Takuma K, Wang $\mathrm{N}$, et al. ABAD directly links Abeta to mitochondrial toxicity in Alzheimer's disease. Science 2004; 304 (5669): 448-52.

60. Nakagawa T, Zhu H, Morishima N, Li E, Xu J, Yankner BA, et al. Caspase-12 mediates endoplasmic-reticulumspecific apoptosis and cytotoxicity by amyloid-beta. Nature 2000; 403 (6765): 98-103.

61. Ghribi O, Herman MM, Savory J. Lithium inhibits Abeta-induced stress in endoplasmic reticulum of rabbit hippocampus but does not prevent oxidative damage and tau phosphorylation. J Neurosci Res 2003; 71 (6): 853-62.

62. Chan SL, Culmsee C, Haughey N, Klapper W, Mattson MP. Presenilin-1 mutations sensitize neurons to DNA damage-induced death by a mechanism involving perturbed calcium homeostasis and activation of calpains and caspase-12. Neurobiol Dis 2002; 11 (1): 2-19.

63. Chretien F, Dorandeu A, Adle-Biassette H, Ereau T, Wingertsmann L, Brion F, et al. [A process of programmed cell death as a mechanisms of neuronal death in prion diseases]. Clin Exp Pathol 1999; 47 (3-4): 181-91.

64. Silveira JR, Raymond GJ, Hughson AG, Race RE, Sim VL, Hayes SF, et al. The most infectious prion protein particles. Nature 2005; 437 (7056): 257-61.

65. Simoneau S, Rezaei H, Sales N, Kaiser-Schulz G, Lefebvre-Roque $\mathrm{M}$, Vidal $\mathrm{C}$, et al. In vitro and in vivo neurotoxicity of prion protein oligomers. PLoS Pathog
2007; 3 (8): e125.

66. Lesne S, Koh MT, Kotilinek L, Kayed R, Glabe CG, Yang A, et al. A specific amyloid-beta protein assembly in the brain impairs memory. Nature 2006; 440 (7082): 352-7.

67. Walsh DM, Klyubin I, Fadeeva JV, Cullen WK, Anwyl R, Wolfe MS, et al. Naturally secreted oligomers of amyloid beta protein potently inhibit hippocampal long-term potentiation in vivo. Nature 2002; 416 (6880): 535-9.

68. Kayed R, Head E, Thompson JL, McIntire TM, Milton SC, Cotman CW, et al. Common structure of soluble amyloid oligomers implies common mechanism of pathogenesis. Science 2003; 300 (5618): 486-9.

69. Eikelenboom P, Bate C, van Gool WA, Hoozemans JJ, Rozemuller JM, Veerhuis R, et al. Neuroinflammation in Alzheimer's disease and prion disease. Glia 2002; 40 (2): 232-9.

70. Streit WJ. Microglia and neuroprotection: implications for Alzheimer's disease. Brain Res Rev 2005; 48 (2): 2349.

71. Rogers J, Lue LF. Microglial chemotaxis, activation, and phagocytosis of amyloid beta-peptide as linked phenomena in Alzheimer's disease. Neurochem Int 2001; 39 (5-6): 333-40.

72. Griffin WS. Inflammation and neurodegenerative diseases. Am J Clin Nutr 2006; 83 (2): 470S-4S.

73. Jiménez S, Baglietto-Vargas D, Caballero C, MorenoGonzález I, Torres M, Sánchez-Varo R, et al. Inflammatory response in the hippocampus of PS1M146L/ APP751SL mouse model of Alzheimer's disease: agedependent switch in the microglial phenotype from alternative to classic. J Neurosci 2008; 28 (45): 11650-61.

74. Moreno-González I, Baglietto-Vargas D, Sánchez-Varo R, Jiménez S, Trujillo-Estrada L, Sánchez-Mejías E, et al. Extracellular amyloid-beta and cytotoxic glial activation induce significant entorhinal neuron loss in young PS1(M146L)/APP(751SL) mice. J Alzheimers Dis 2009; 18 (4): 755-76.

75. Brown DR. Microglia and prion disease. Microsc Res Tech 2001; 54 (2): 71-80.

76. Polazzi E, Monti B. Microglia and neuroprotection: from in vitro studies to therapeutic applications. Prog Neurobiol 2010; 92 (3): 293-315.

77. Akiyama H, Barger S, Barnum S, Bradt B, Bauer J, Cole GM, et al. Inflammation and Alzheimer's disease. Neurobiol Aging 2000; 21 (3): 383-421.

78. Thal DR, Rub U, Orantes M, Braak H. Phases of A beta-deposition in the human brain and its relevance for the development of AD. Neurology 2002; 58 (12): 1791-800

79. Duyckaerts C, Potier MC, Delatour B. Alzheimer disease models and human neuropathology: similarities and 
differences. Acta Neuropathol 2008; 115 (1): 5-38.

80. Sasaki A, Yamaguchi H, Ogawa A, Sugihara S, Nakazato Y. Microglial activation in early stages of amyloid beta protein deposition. Acta Neuropathol (Berl) 1997; 94 (4): 316-22.

81. Malm TM, Koistinaho M, Parepalo M, Vatanen T, Ooka A, Karlsson S, et al. Bone-marrow-derived cells contribute to the recruitment of microglial cells in response to beta-amyloid deposition in APP/PS1 double transgenic Alzheimer mice. Neurobiol Dis 2005; 18 (1): 134-42.

82. Meyer-Luehmann M, Spires-Jones TL, Prada C, GarcíaAlloza M, de CA, Rozkalne A, et al. Rapid appearance and local toxicity of amyloid-beta plaques in a mouse model of Alzheimer's disease. Nature 2008; 451 (7179): 720-4.

83. Frautschy SA, Cole GM, Baird A. Phagocytosis and deposition of vascular beta-amyloid in rat brains injected with Alzheimer beta-amyloid. Am J Pathol 1992; 140 (6): 1389-99.

84. Weldon DT, Rogers SD, Ghilardi JR, Finke MP, Cleary JP, O'Hare E, et al. Fibrillar beta-amyloid induces microglial phagocytosis, expression of inducible nitric oxide synthase, and loss of a select population of neurons in the rat CNS in vivo. J Neurosci 1998; 18 (6): 2161-73.

85. Simard AR, Soulet D, Gowing G, Julien JP, Rivest S. Bone marrow-derived microglia play a critical role in restricting senile plaque formation in Alzheimer's disease. Neuron 2006; 49 (4): 489-502.

86. Bolmont T, Haiss F, Eicke D, Radde R, Mathis CA, Klunk WE, et al. Dynamics of the microglial/amyloid interaction indicate a role in plaque maintenance. J Neurosci 2008; 28 (16): 4283-92.

87. Colton CA, Mott RT, Sharpe H, Xu Q, Van Nostrand WE, Vitek MP. Expression profiles for macrophage alternative activation genes in $\mathrm{AD}$ and in mouse models of AD. J Neuroinflammation 2006; 3: 27.

88. Williams AE, Lawson LJ, Perry VH, Fraser H. Characterization of the microglial response in murine scrapie. Neuropathol Appl Neurobiol 1994; 20 (1): 47-55.

89. El KJ, Toft M, Hickman SE, Means TK, Terada K, Geula $\mathrm{C}$, et al. Ccr2 deficiency impairs microglial accumulation and accelerates progression of Alzheimer-like disease. Nat Med 2007; 13 (4): 432-8.

90. Johnstone M, Gearing AJ, Miller KM. A central role for astrocytes in the inflammatory response to betaamyloid; chemokines, cytokines and reactive oxygen species are produced. J Neuroimmunol 1999; 93 (1-2): 182-93.

91. Tuppo EE, Arias HR. The role of inflammation in Alzheimer's disease. Int J Biochem Cell Biol 2005; 37 (2):
289-305.

92. Funato H, Yoshimura M, Yamazaki T, Saido TC, Ito Y, Yokofujita J, et al. Astrocytes containing amyloid betaprotein (Abeta)-positive granules are associated with Abeta40-positive diffuse plaques in the aged human brain. Am J Pathol 1998; 152 (4): 983-92.

93. Kurt MA, Davies DC, Kidd M. beta-Amyloid immunoreactivity in astrocytes in Alzheimer's disease brain biopsies: an electron microscope study. Exp Neurol 1999; 158 (1): 221-8.

94. Nagele RG, D'Andrea MR, Lee H, Venkataraman V, Wang HY. Astrocytes accumulate A beta 42 and give rise to astrocytic amyloid plaques in Alzheimer disease brains. Brain Res 2003; 971 (2): 197-209.

95. Muramori F, Kobayashi K, Nakamura I. A quantitative study of neurofibrillary tangles, senile plaques and astrocytes in the hippocampal subdivisions and entorhinal cortex in Alzheimer's disease, normal controls and nonAlzheimer neuropsychiatric diseases. Psychiatry Clin Neurosci 1998; 52 (6): 593-9.

96. Schultz J, Schwarz A, Neidhold S, Burwinkel M, Riemer C, Simon D, et al. Role of interleukin-1 in prion diseaseassociated astrocyte activation. Am J Pathol 2004; 165 (2): 671-8.

97. Burwinkel M, Riemer C, Schwarz A, Schultz J, Neidhold $\mathrm{S}$, Bamme T, et al. Role of cytokines and chemokines in prion infections of the central nervous system. Int J Dev Neurosci 2004; 22 (7): 497-505.

98. Soto C, Satani N. The intricate mechanisms of neurodegeneration in prion diseases. Trends Mol Med 2010.

99. McGeer PL, Schulzer M, McGeer EG. Arthritis and anti-inflammatory agents as possible protective factors for Alzheimer's disease: a review of 17 epidemiologic studies. Neurology 1996; 47 (2): 425-32.

100. Anthony JC, Breitner JC, Zandi PP, Meyer MR, Jurasova $\mathrm{I}$, Norton $\mathrm{MC}$, et al. Reduced prevalence of $\mathrm{AD}$ in users of NSAIDs and $\mathrm{H} 2$ receptor antagonists: the Cache County study. Neurology 2000; 54 (11): 2066-71.

101. Stewart WF, Kawas C, Corrada M, Metter EJ. Risk of Alzheimer's disease and duration of NSAID use. Neurology 1997; 48 (3): 626-32.

102. Weggen S, Eriksen JL, Das P, Sagi SA, Wang R, Pietrzik $\mathrm{CU}$, et al. A subset of NSAIDs lower amyloidogenic Abeta42 independently of cyclooxygenase activity. Nature 2001; 414 (6860): 212-6.

103. Lim GP, Yang F, Chu T, Chen P, Beech W, Teter B, et al. Ibuprofen suppresses plaque pathology and inflammation in a mouse model for Alzheimer's disease. J Neurosci 2000; 20 (15): 5709-14.

104. Yan Q, Zhang J, Liu H, Babu-Khan S, Vassar R, Biere $\mathrm{AL}$, et al. Anti-inflammatory drug therapy alters beta- 
Agregados amiloides y desórdenes de conformación proteica - C. Durán-Aniotz et al

amyloid processing and deposition in an animal model of Alzheimer's disease. J Neurosci 2003; 23 (20): 7504-9.

105. Hillmann A, Hahn S, Schilling S, Hoffmann T, Demuth $\mathrm{HU}$, Bulic B, et al. No improvement after chronic ibuprofen treatment in the 5XFAD mouse model of Alzheimer's disease. Neurobiol Aging 2012; 33 (4): 833-50.

106. Jaturapatporn D, Isaac MG, McCleery J, Tabet N. Aspirin, steroidal and non-steroidal anti-inflammatory drugs for the treatment of Alzheimer's disease. Cochrane Database Syst Rev 2012; 2:CD006378.

107. Gilman S, Koller M, Black RS, Jenkins L, Griffith SG, Fox NC, et al. Clinical effects of A $\{$ beta $\}$ immunization (AN1792) in patients with $\mathrm{AD}$ in an interrupted trial. Neurology 2005.

108. Wisniewski T, Sigurdsson EM. Therapeutic approaches for prion and Alzheimer's diseases. FEBS J 2007; 274 (15): 3784-98.

109. Griffin JK, Cashman NR. Progress in prion vaccines and immunotherapies. Expert Opin Biol Ther 2005; 5 (1): 97-110.

110. Esposito E, Cuzzocrea S. New therapeutic strategy for Parkinson's and Alzheimer's disease. Curr Med Chem 2010; 17 (25): 2764-74.
111. Wilcock GK, Black SE, Hendrix SB, Zavitz KH, Swabb EA, Laughlin MA. Efficacy and safety of tarenflurbil in mild to moderate Alzheimer's disease: a randomised phase II trial. Lancet Neurol 2008; 7 (6): 483-93.

112. Soto C, Kascsak RJ, Saborio GP, Aucouturier P, Wisniewski T, Prelli F, et al. Reversion of prion protein conformational changes by synthetic beta-sheet breaker peptides. Lancet 2000; 355 (9199): 192-7.

113. Aguzzi A, Sigurdson CJ. Antiprion immunotherapy: to suppress or to stimulate? Nat Rev Immunol 2004; 4 (9): 725-36.

114. Heppner FL, Musahl C, Arrighi I, Klein MA, Rulicke T, Oesch B, et al. Prevention of scrapie pathogenesis by transgenic expression of anti-prion protein antibodies. Science 2001; 294 (5540): 178-82.

115. White AR, Enever P, Tayebi M, Mushens R, Linehan J, Brandner S, et al. Monoclonal antibodies inhibit prion replication and delay the development of prion disease. Nature 2003; 422 (6927): 80-3.

116. Carnaud C, Bachy V. Cell-based immunotherapy of prion diseases by adoptive transfer of antigen-loaded dendritic cells or antigen-primed CD (4+) T lymphocytes. Prion 2010; 4 (2): 66-71. 